Supplement of

\title{
Vertical dependence of horizontal variation of cloud microphysics: observations from the ACE-ENA field campaign and implications for warm-rain simulation in climate models
}

Zhibo Zhang et al.

Correspondence to: Zhibo Zhang (zhibo.zhang@umbc.edu)

The copyright of individual parts of the supplement might differ from the CC BY 4.0 License. 

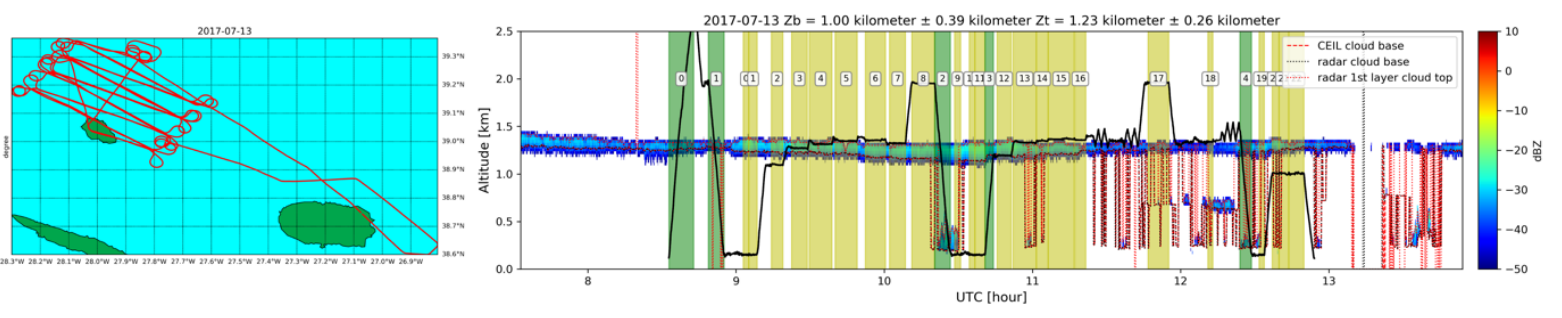

Figure S1 Same as Figure 1 of the paper, except for RF 2017-07-13
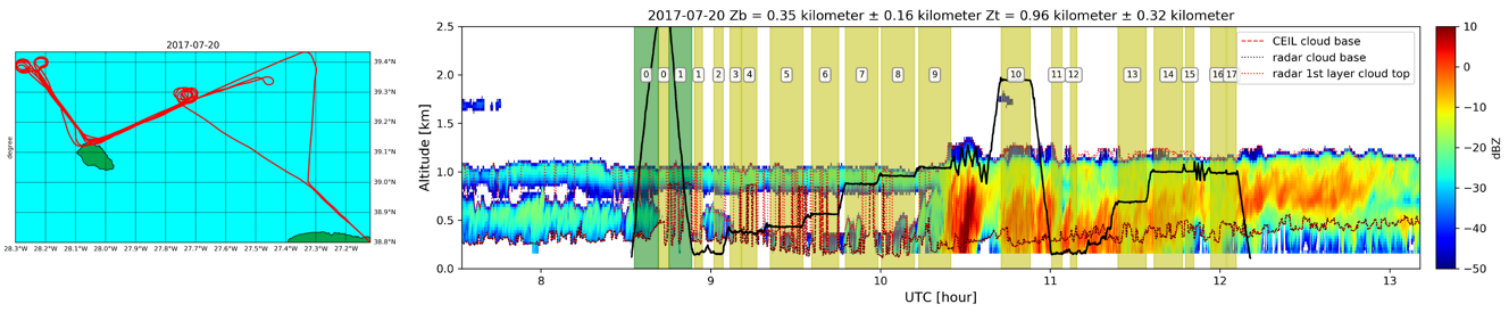

Figure S2 Same as Figure 1 of the paper, except for RF 2017-07-20
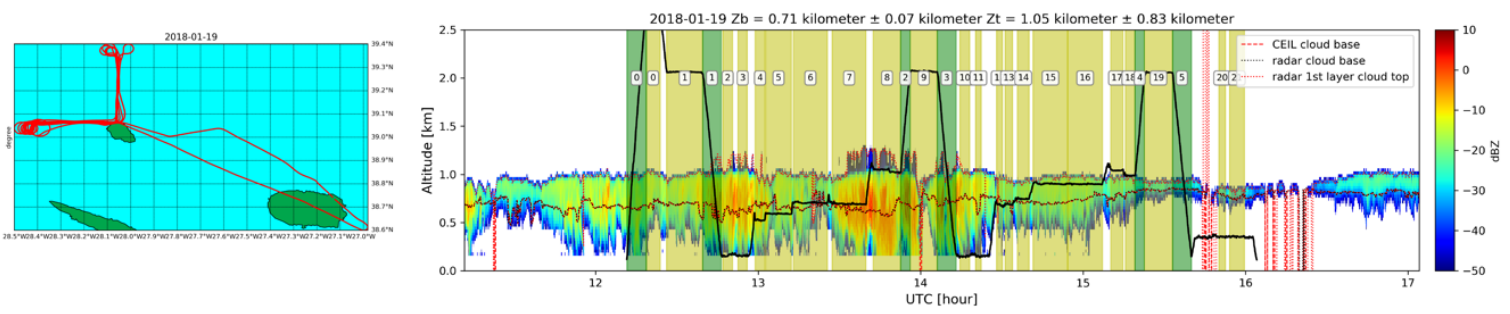

Figure S 3 Same as Figure 1 of the paper, except for RF 2018-01-19 

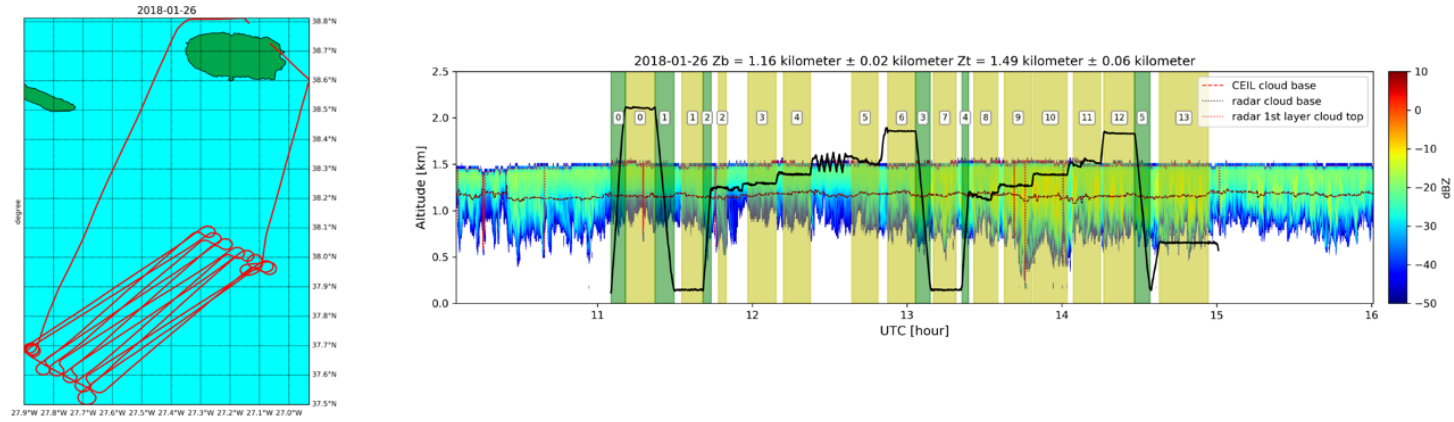

Figure S4 Same as Figure 1 of the paper, except for RF 2018-01-26

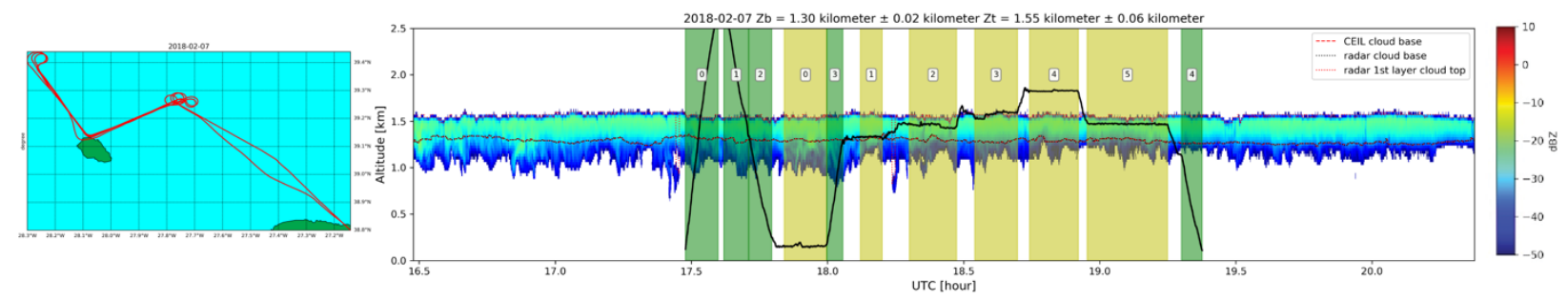

Figure S5 Same as Figure 1 of the paper, except for RF 2018-02-07
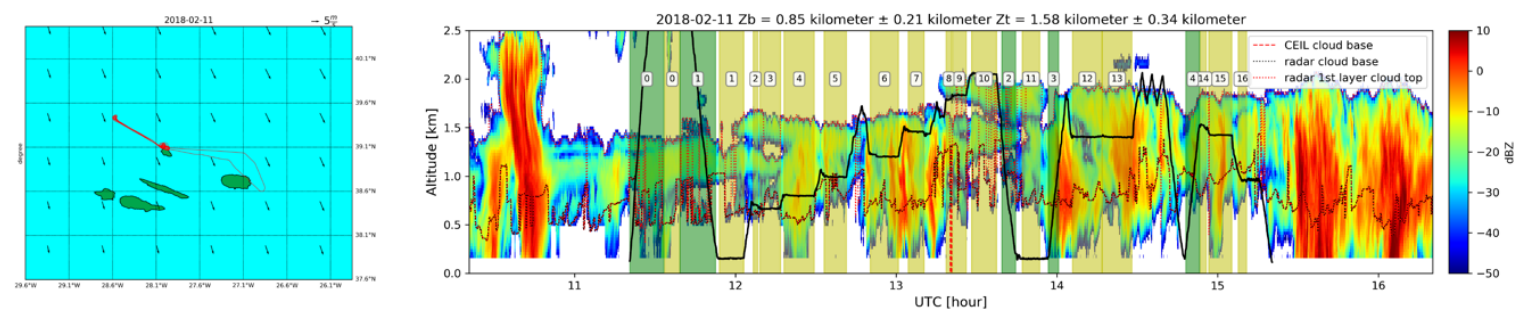

Figure S6 Same as Figure 1 of the paper, except for RF 2018-02-11 